\title{
Moldeando identidad en los talleres alfareros de San Juan de Oriente
}

Arql. Kevin González Hodgson Investigador del Centro Arqueológico de Documentación e Investigación Máster en Métodos de Investigación Científica FAREM-Carazo

CADI-UNAN-Managua

hodgsonk27@hotmail.com

Palabras Clave: Cultura, Identidad cultural, alfarería, globalización, San Juan de Oriente.

\section{RESUMEN}

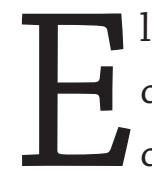
1 presente artículo hace un esbozo general sobre la producción de diseños cerámicos que configuran la identidad cultural de San Juan de Oriente, Masaya, considerando que su cultura material es resultado de la herencia transmitida por generaciones en el tiempo y ha estado sujeta a modelos alienantes y correlacionados al fenómeno de globalización cuya tendencia ha penetrado el orden sociocultural local, motivando una variabilidad en la forma y contenido de elaborar diseños cerámicos. Los resultados exponen de manera sintetizada, la situación actual sobre la producción alfarera en los talleres frente al sistema de mercado que impera hoy así, como la puesta de un catálogo cerámico que tiene utilidad práctica, por cuanto, recoge un registro visual de diseños morfológicos y decorativos de origen prehispánicos que contribuyen a la revitalización del arte cerámico de sus creadores mediante la enseñanza de valores y conocimientos propios de su cultura, aportando de esta manera al fortalecimiento de su identidad.

\section{INTRODUCCIÓN}

A decir verdad, resumir en unas cuantas páginas la realidad artística y cultural de los artesanos de San Juan de Oriente es sin duda, tarea compleja sobre todo, porque estimulan a escudriñar en los orígenes del arte de aquellas sociedades dispuestas sobre la Meseta de los Pueblos, previo al advenimiento de conquista y colonización española en el pacífico del país. 
Sin duda alguna, la alfarería de San Juan de Oriente ha recibido una amplia atención de parte de los medios televisivos y escrito, sin embargo, muy poco se ha tratado de analizar el tema de producción frente a los procesos significativos y correlacionados, como lo es el fenómeno de la globalización cuya tendencia ha afectado el orden socio-cultural a escala local y con ello motivando una diversificación de estilos cerámicos precisamente a raíz de su carácter universal y de uniformidad.

Desde esa premisa, la producción alfarera implica una conexión entre pasado y presente, por lo que en el caso del municipio en estudio, se materializa en acervos tangibles e intangibles, es decir, verdaderas obras maestras que confirman que una de las mejores fortalezas en la actualidad es la elaboración de piezas cerámicas con motivos precolombinos, contemporáneos y utilitarios, resultado de la combinación de elementos particulares tierra, agua, fuego y viento.

Para lograr los objetivos planteados y corroborar la hipótesis inicial, el estudio se abordó desde un enfoque teórico-metodológico orientado desde la investigación cualitativa considerada en un sentido amplio como "aquella que produce datos descriptivos: las propias palabras de las personas, habladas o escritas y la conducta observable" (Taylor y Bogdan, 1987:20) y sustentado además, en la teoría antropológica del método etnográfico y técnicas particulares de este, como la observación participante, entrevista semiestructurada (Flick, 2004:99) y bajo el principio de "vivir cultura".

La investigación está organizada en cuatro secciones. La sección inicial, trata sobre el contexto geográfico e histórico del objeto de estudio. La segunda, contiene una descripción de las modalidades o estilos cerámicos que se elaboran en los talleres alfareros.

La tercera sección, aborda la diversidad estilística de piezas, resultado del proceso de globalización y los sistemas de mercado que se imponen en la actualidad. Finalmente, el cuarto apartado resalta la importancia del catálogo cerámico y su contribución para el fortalecimiento de los talleres alfareros.

\section{Contexto geográfico e histórico de San Juan de Oriente}

Los seres humanos están socialmente ubicados y culturalmente construidos, por lo que cobra importancia comprender el espacio dotado de significado (Benedetto, 2006:12). San Juan de Oriente se sitúa en la franja del pacífico de Nicaragua, precisamente en el sector sureste del departamento de Masaya, perteneciente a la llamada Meseta de los Pueblos, precisamente ubicado dentro de la caldera de Apoyo y la parte oeste del municipio.

Los testimonios más tempranos sobre el poblamiento nacional, son los respaldados por fuentes etnohistóricas que sostienen que él mismo fue poblado por múltiples migraciones procedentes del norte y sur del continente. Lejanamente, la zona en estudio fue ocupado por una 
confederación de pueblos indígenas conocido como "Valle de Namotiva", previo al advenimiento español.

Al respecto, entre el 500-1520 d.C., los chorotegas ${ }^{2}$ hablantes del mangue habrían llegado al pacífico nicaragüense procedentes del norte de Mesoamérica y lingüísticamente pertenecientes al grupo chiapaneco-mangue divididos en Ocan-Siux, Oto-Mangue (Constenla, 1994:200) y UtoAzteca, conformada por los Maribios (Sutiaba), Mangues (Chorotegas), seguidos varios siglos después, por los nicaraos, ocasionando conflictos territoriales que habrían suscitado una oleada migratoria de los primeros más al sur de la actual Península de Nicoya.

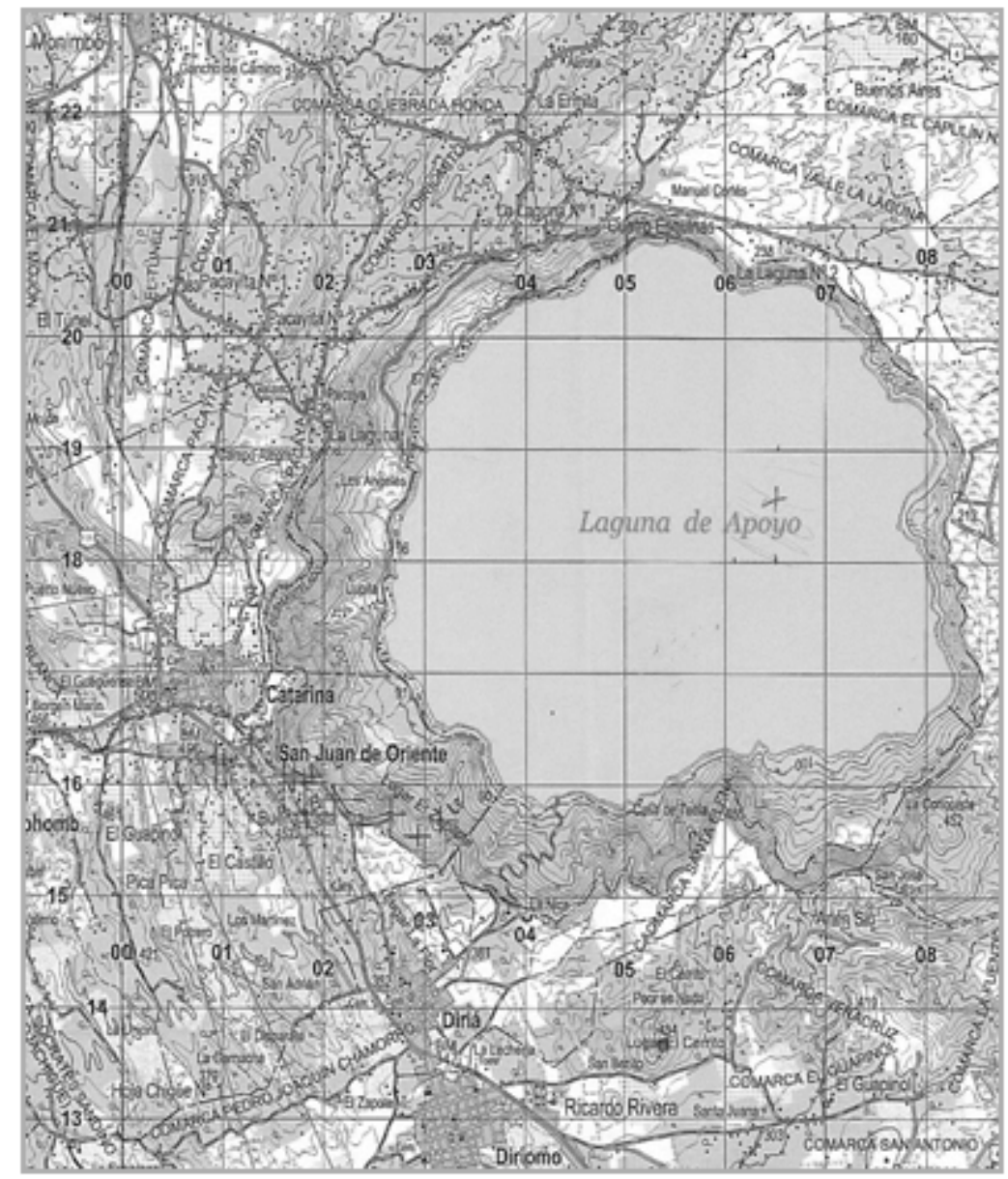

Mapa 1. Topografía y poblados colindantes con el municipio de San Juan de Oriente entre ellos están: Catarina, Niquinohomo, Diriá, Diriomo. Fuente: CADI-UNAN-Managua.

En ese caso, la historia antigua de Nicaragua está ligada en el pasado con la región de Gran Nicoya, ya que es referente para entender su producción cerámica que "a lo largo del $800 y$ el 1523 d.C será el más popular y conocido" (Palomar y Gassiot, 1996:3) al grado que su cerámica polícroma fue caracterizada por el uso de diferentes colores, formas y diseños de claros rasgos mesoamericanos (Castegnaro, 1992:152, citado en Balladares y Lechado, 2005: 152). Esa

1. En lengua Náhuatl significa pueblos hermanos.

2. De los siete grupos de lenguas que consta esta familia, el único extinto es el grupo chiapaneco-mangue y el resto se hablan en México. 
cerámica constituyó un elemento esencial, tanto en el ámbito económico y social de Chorotegas y Nicarao.

San Juan de Oriente se encuentra dentro de esa subárea cultural y su conexión con la cultura mesoamericana aún está presente, es decir, la herencia de este pueblo es su trabajo artesanal no solo cerámico sino también, el trabajo en piedra (ídolos y piedras de moler) oficio que tiene su referente, precisamente en el arte prehispánico, al punto que sus artesanos han cultivado con mucha calidad dicho arte, a pesar del contexto actual con el que se enfrenta la producción alfarera del país.

En tanto, la historiografía, la arqueología, así como el análisis documental explican que la región dela Meseta de los Pueblos y San Juan de Oriente fueron parte del corredor mesoamericano y constituido en importantes centros de producción cerámica, elaborando entre otros estilos: papagayo, vallejo y pataky polícromos hasta la llegada de los españoles, lo que explicaría que la actividad alfarera no fue una simple casualidad, al contrario el artista precolombino trabajó a la perfección la piedra y la cerámica destacándose en ella elementos antropomorfos y zoomorfos típicos de influencia mesoamericana (Ferrero, 2000:24), por lo que causó asombro y admiración en el invasor europeo, sobre todo, por su belleza y estética singular llena de identidad.

\section{MATERIAL Y MÉTODOS}

Se realizó un estudio descriptivo y analítico con una fase inicial exploratoria en la que se describe situaciones, eventos y hechos de manera espontánea. La metodología utilizada corresponde al tipo de investigación cualitativa basada en la teoría etnográfica y técnicas propias como la observación participante, por cuanto, actuamos en un mundo social y somos capaces de vernos a nosotros y a nuestras acciones como objetos de ese mundo (Hammersley y Atkinson, 1994:40). La adopción del método etnográfico, en este caso, es holística y contextual, al punto que brindó descripciones en detalle y utiliza para ello, las propias palabras de los artesanos a partir de la conducta observada y recordada de aquellos hechos afines a la práctica de elaborar cerámica en la localidad.

Además de observar el estudio, se propuso preguntar y examinar apoyándose en la adopción de instrumentos de recolección de datos como la entrevista semiestructurada, también del diseño de encuestas, lo que incurrió en la selección del muestreo, la recolección de datos y su posterior análisis estadístico; la unidad de análisis la constituyeron 50 artesanos de las zonas urbanas 1, 2 y 3, además, de El Castillo, El Tempisque, Buena Vista, sector Los López, establecido mediante muestra no probabilística de tipo intencional basado en los siguientes criterios:

1. Artesanos que habitaran en la localidad

2. Artesanos que tuvieran taller o empresa dedicada a la elaboración alfarera 
3. Artesanos con al menos quince años de experiencia en la elaboración alfarera

4. Artesanos que su práctica artesanal fuese heredada de generación en generación

5. Artesanos que tuvieran la disposición de entregar información y fiabilidad

Po otra parte, el estudio incluyó la metodología del grupo focal, por ser una estrategia de indagación que ofreció a los participantes una mayor flexibilidad en la manera de responder, y desarrollado en un ambiente abierto, con intercambio de ideas y obtención de mayores datos. Finalmente, todo el proceso fue acompañado de la aplicación de técnicas de investigación documental y técnicas propiamente de campo que garantizó triangular datos, es decir, cotejar ideas y triangular resultados.

\section{La cuestión de los estilos cerámicos en San Juan de Oriente}

El estudio de la alfarería de San Juan de Oriente invita a preguntarnos directa o indirectamente, ¿qué es lo que define y diferencia su producción cerámica con respecto al resto del país?, o aún más importante, ¿cómo identificar rasgos de persistencia prehispánica en la elaboración de los actuales diseños y formas cerámicas? Esto, sobre todo, porque sus creadores han asumido esta práctica como parte de su conexión con la tradición cultural mesoamericana, particularmente con sus antepasados Chorotegas.

En efecto, la historia de la cerámica como actividad manufacturera y artística ha estado asociada a la conformación de las identidades particulares y colectivas de cada sociedad, y el caso de la actividad alfarera prehispánica no fue una casualidad y tampoco rara, ya que "en toda Mesoamérica tenemos casos donde la alfarería representa el rasgo residual de una identidad étnica histórica" (Castegnaro de Folletti, 1992). En el caso de la alfarería de San Juan de Oriente, se ha practicado en la región desde antes del contacto español y su proceso evolutivo fue caracterizado por una fase inicial con la llamada alfarería utilitaria o rústica, entre ellos, la elaboración de los "juguetes de barro" (ocarinas y flautas) en miniaturas que se producían en la década de los años 60 y 70, determinados por una manufactura tosca y escasa pintura, debido a que los talleres tenían herramientas y hornos inadecuados por lo que las quemas se realizaban a temperaturas bajas y hoy, tienden a desaparecer por su escasa incorporación de tecnología, de baja productividad y rentabilidad. Además, la localidad se especializaba en la elaboración de vasijas abiertas: platos con base redondeada, cazuelas, vasos, ollas, tinajas, comales y vasijas cerradas: jarro vertedor, tacitas con una o dos asas de labio inclinado al exterior y borde de tendencia apuntada que a pesar del tiempo, estos son utilizados en funciones domésticas locales a decir, para cocer fríjoles, freír arroz, almacenar agua, preparar el café, tostar tortillas entre otros.

Subsiguientemente, en 1975, el departamento de investigaciones tecnológicas del BCN consideró oportuno reactivar el tema artesanal en el país y con ello, la apertura de la escuela- 
taller y la implementación de nuevas técnicas y tecnologías a la producción artesanal, sobre todo, con fines industriales; esa iniciativa contó con la participación de instructores nacionales e internacionales. En ese contexto, los diseños precolombinos eran la principal línea, inspirados en la obra del antropólogo norteamericano Samuel Lothrop (1926) "Cerámica de Costa Rica y Nicaragua". Las formas son vasijas abiertas: cuencos, escudilla, vasos cilíndricos, trípodes, ánforas, jarrones ovoides y periformes con base de pedestal, geometría casi exacta y con iconografías como el lagarto, jaguar, chompipes, silueta de conejo y la serpiente emplumada que ha permanecido por muchas generaciones además, de geometría: líneas paralelas, triángulos y grecas.

Los hallazgos indican que la manufactura de los diseños precolombinos, identificados en los talleres, fueron producidos con al menos más de 600 años en regiones del pacífico de Nicaragua y Costa Rica en lo que constituía la Gran Nicoya y del que hoy el artesano ha asumido como réplicas precolombinas a decir, de los tipos descritos: Potosí Aplicado (500-1350 d.C. P. Bagaces), Sacasa Estriado (800-1520 d. C. P. Sapoá) Papagayo Polícromo (800-1350 d.C. P. Sapoá), además, Pataky Polícromo (800-1350 d.C.) y Luna Polícromo (1250-1550 d.C. P. Ometepe).

El matiz de los diseños contemporáneos tiene su referente en el arte precolombino y sus motivos más puntuales son la geometría en las piezas, es decir, el artesano presta atención a la incorporación de líneas verticales y horizontales, triángulos y en ocasiones, hace uso de grecas y figuras zoomorfas o la fusión antropomorfo-zoomorfo, asimismo, de temas como naturaleza, peces, venados, aves, ranas, tortugas, monos, águila. Las formas son varias, desde platos, jarrones globulares y ovoides en posición invertida, recurvados, cilíndricos, tazones de bordes recurvados hacia afuera. Una sublínea de esta práctica es el estilo libre donde resaltan floreros, botellas, campanas, piezas de pared aplicando acrílico, óleo y agua, el "chancomido" o incisión y técnicas emergentes como el "calado inciso".

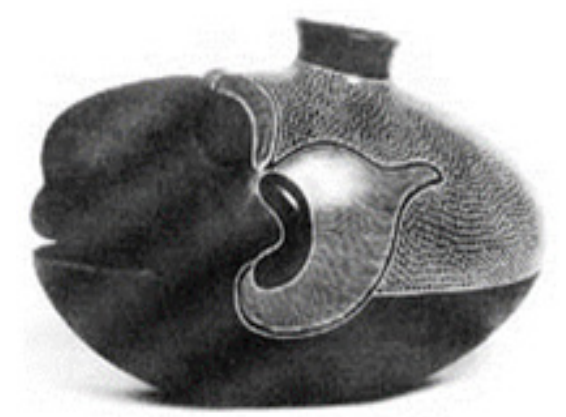

Figura 1. Obra de arte titulado, "el hombre pez" elaborado por Helio Gutiérrez. Esta obra obtuvo en 1998 el primer premio de artesanía, creada por la UNESCO. Cortesía: Don Helio Gutiérrez. 
La alfarería local se realiza en algunos casos con herramientas rudimentarias y materia primas locales extraídas de los patios de las $\operatorname{casas}^{3}$, por lo que este recurso sugiere un conocimiento resguardado por medio de la costumbre y que podría remontarse al periodo prehispánico. Dicho proceso nace de la "cotidianidad" de sus creadores y en él intervienen una serie de procesos, atributos y técnicas Cremonte (1985), Ferrero (1987) y Orton et al (1997) que deben cumplirse antes de pasar a la siguiente etapa. La arcilla se extrae a golpes de pico, barra y pala, posteriormente, en los talleres artesanales familiares se extiende en "petates" o "sacos macen" y se deja secar al sol, luego se limpia y elimina impurezas, entre ellas, piedras, raíces, mediante la técnica de "espulgar", después se remoja por algunos días (maduración de la pasta arcillosa) y amasado final haciendo uso de los pies para luego guardarla y que no pierda humedad.

Posteriormente, el proceso siguiente es el de "formatización", es decir, modelado de las piezas y tratamientos previos y posteriores al proceso de cocción o quema, para luego finalizar con el proceso de comercialización. El trabajo en los talleres se divide entre los miembros; por lo general, el esposo elabora las piezas manualmente o haciendo uso del torno y las mujeres trabajan en el tratamiento superficial y decoración. Estéticamente, los estilos alfareros se caracterizan por una riqueza en sus diseños que hacen que el visitante las contemple y descubra la personalidad que le imprime cada artesano con decoraciones excepcionales, colores vivos y dibujos que están asociados a menudo a temas cotidianos y comerciales, en algunos casos, cósmicos o simplemente representan el relajamiento de determinadas tensiones y emociones interiores que permiten al artista exteriorizar sus ideas a través, del arte como expresión de cultura individual o colectiva, de manera, que las artes no son simplemente artes de ver, son artes para descifrar, leer, entender, interpretar (Velásquez, 2003:35).

3. En el caso de materias primas como el "engobe o talgüe" proviene de El Sauce y Cinco Pinos en el occidente del país.

4. El saco de barro amasado en algunos puestos de venta se cotiza en 180-250 córdobas. 
Tabla 1. Estructura y tipología cerámica identificada en los talleres de San Juan de Oriente

\begin{tabular}{|c|c|c|c|}
\hline & MAS & MODALIDAD & T. MANUFACTURA \\
\hline \multirow{5}{*}{ Vasijas } & Botella & \multirow{5}{*}{$\begin{array}{l}\text { Utilitario/Precolombino/ } \\
\text { Contemporáneo }\end{array}$} & \multirow{5}{*}{$\begin{array}{l}\text { Modelado por presión, } \\
\text { aplicación, escultóricas, } \\
\text { alto relieve, torno alfarero }\end{array}$} \\
\hline & Olla & & \\
\hline & Tinaja & & \\
\hline & Cuenco & & \\
\hline & Cuenco/Escudilla & & \\
\hline \multirow{3}{*}{$\begin{array}{l}\text { Utensilios de } \\
\text { Cocina }\end{array}$} & Tazas & \multirow{3}{*}{ Utilitario } & \multirow{3}{*}{$\begin{array}{c}\text { Modelado por presión, } \\
\text { aplicación }\end{array}$} \\
\hline & Cucharas & & \\
\hline & Plato & & \\
\hline \multirow{4}{*}{ Ornamento } & Florero & \multirow{4}{*}{ Utilitario/Estilo Libre } & \multirow{4}{*}{$\begin{array}{l}\text { Modelado por presión, } \\
\text { aplicación, escultóricas }\end{array}$} \\
\hline & Máscaras & & \\
\hline & Adorno de techo & & \\
\hline & Cumbreras & & \\
\hline \multirow{3}{*}{ I. Musicales } & Flautas & \multirow{3}{*}{ Estilo Libre } & \multirow{3}{*}{$\begin{array}{l}\text { Modelado por presión, } \\
\text { aplicación, incisiones, } \\
\text { aplicaciones y otros }\end{array}$} \\
\hline & Silbatos & & \\
\hline & Ocarinas & & \\
\hline Figurillas & Miniaturas & Precolombino/utilitario & $\begin{array}{c}\text { Modelado por presión, } \\
\text { aplicación }\end{array}$ \\
\hline
\end{tabular}




\section{REPRESENTACIÓN GRÁFICA}

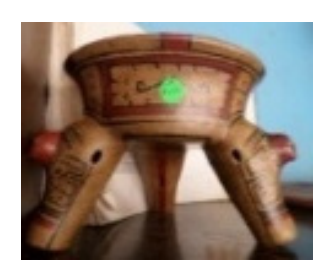

Fig2.

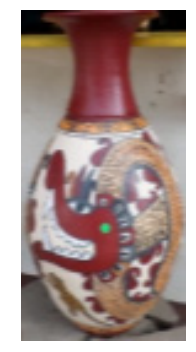

Fig6.

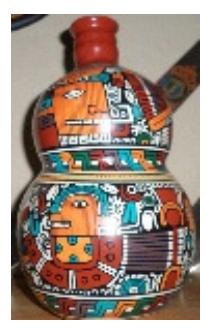

Fig10.
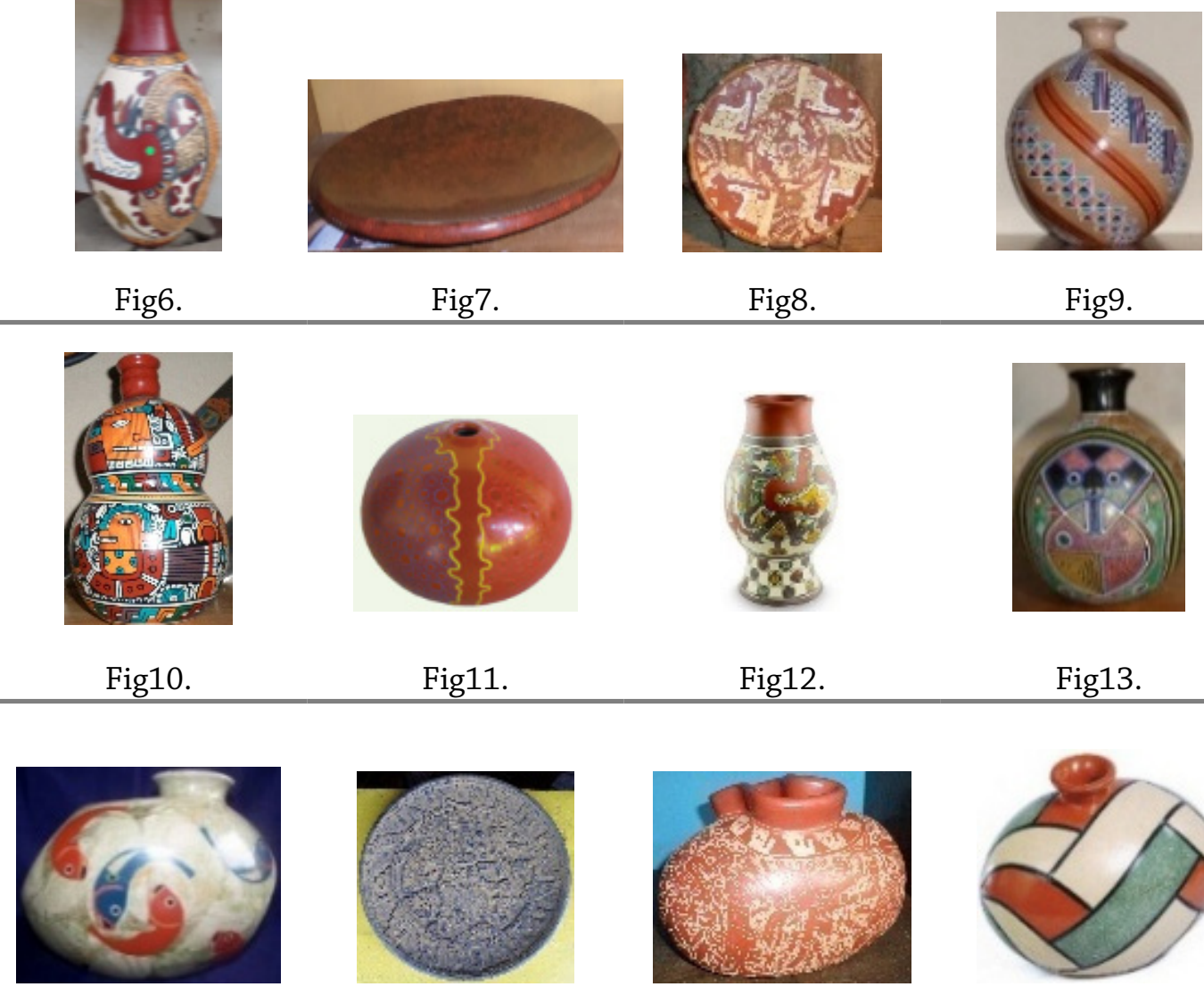

Fig8.
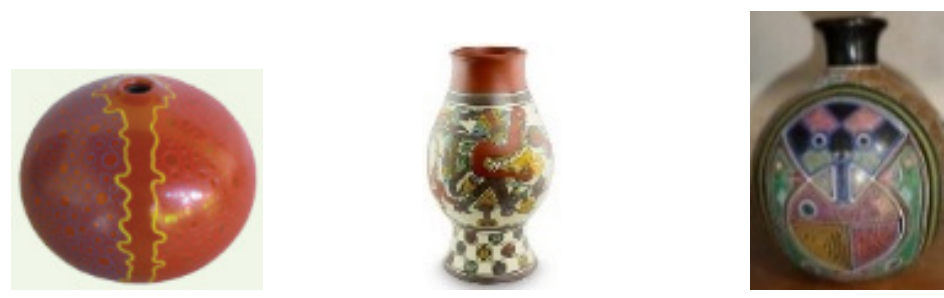

Fig12.
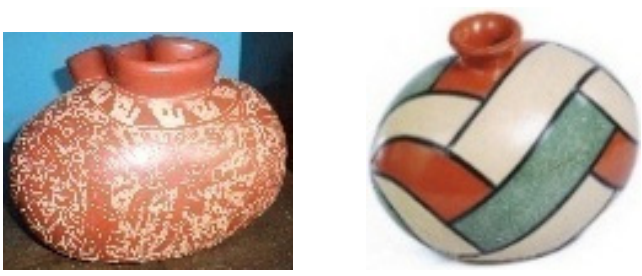

Fig18.

Fig17.
Fig15.

Fig16.

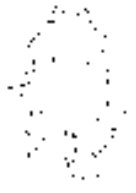

Fig21

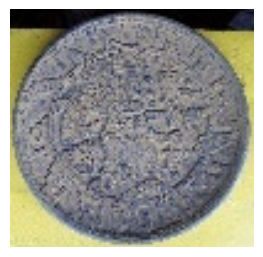

Fig16.

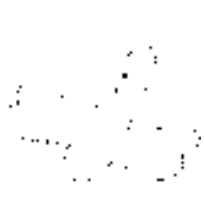

Fig20.

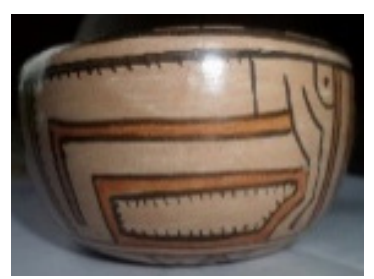

Fig5.
Fig9.

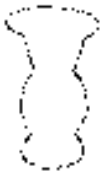

Fig22.

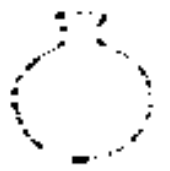

Fig23.
Diseños

contemporáneos:

técnicas del

"chancomido, cadenas de cuadros, triangulos, líneas entrelazados y diseños zoomorfos, además de la técnica del calado inciso.

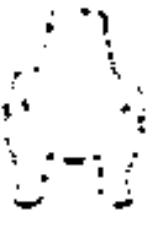

Fig14.

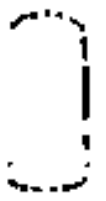

Fig19.

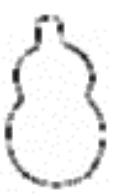

Fig.24 


\section{Globalización y producción alfarera: la diversificación de estilos cerámicos}

Como ya se ha apuntado, la producción alfarera inscribe ciertos valores culturales y aspectos simbólicos que desde los mismos artesanos han internalizado en sus acciones, en sus relaciones sociales y en los objetos cerámicos que elaboran, sin embargo, esa vigencia de rasgos en los talleres se encuentra bajo la premisa de potenciales amenazas de extinción o sustitución de técnicas y formas tradicionales de manufactura por nuevas formas que son generadas por el tipo de demanda comercial y los efectos de políticas económicas implementadas en virtud delos cuales, los Estados Nacionales soberanos entremezclan e imbrican mediante actores trasnacionales y sus respectivas probabilidades de poder, orientaciones, identidades y entramados varios" (Beck, 1998:27).

En ese sentido, los hallazgos indican que, los diseños se encuentran supeditados a intereses propios del mercado oferta y demanda, lo que confirma que los mismos no precisamente representen una continuidad y tradición sin ruptura o "una secuencia de acciones, cohesión y de identidad como unidad repetitiva cuasi-estable (Nash, 1975: 54, Piaget, 1952: 224 y Flavell, 1963: 224 citado en Carrasco, 2002: 58) al contrario, hoy el oficio ha experimentado cambios en su metodología con la incorporación del uso del torno como principal técnica en un 74 \% ya que agiliza el proceso de manufactura.

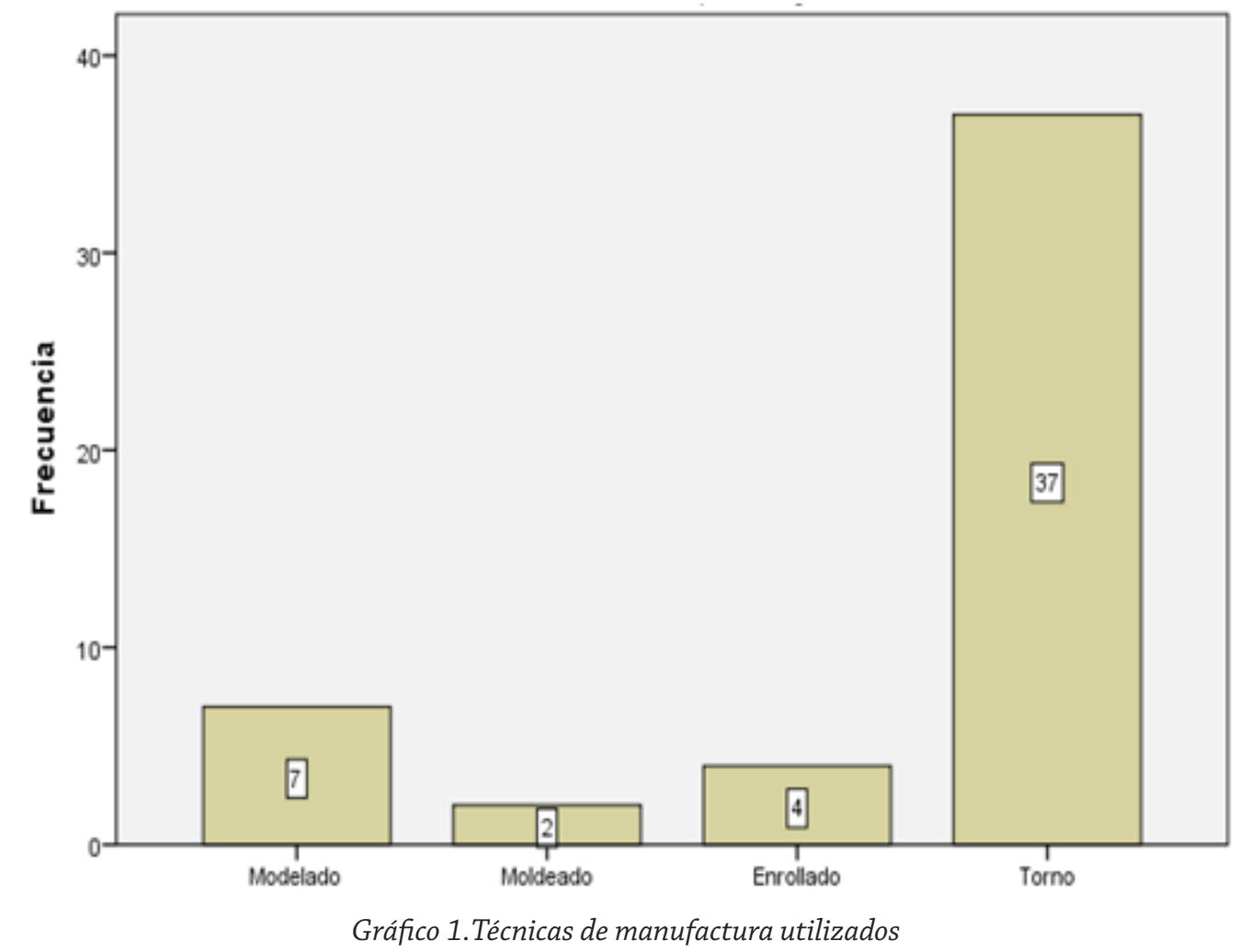

En consecuencia, buena parte de la producción de artesanía, y en particular el de la cerámica tradicional, está desapareciendo en muchas partes del mundo, al ser absorbidos los 
grupos productores por sociedades de corte capitalista (García Rosselló, 2008:47) y en el caso de San Juan de Oriente, quedó integrado en la dinámica capitalista de finales del siglo XX, al punto que generó transformaciones notorias. Por un lado, se dejaron de producir objetos que ya no eran necesarios en la sociedad moderna; y segundo, porque el artesano no fue capaz de competir con los productos industriales, lo que no significa que su manufactura alfarera esté desapareciendo, pero sí, al tema se le ha incorporado matices de "hibridación" resultado del proceso de modernización cultural a través de la difusión de los medios de comunicación, esto quiere decir, que "la mayoría de los bienes y los mensajes que recibe diariamente cada pueblo han sido generados fuera de su territorio o en empresas trasnacionales, que aun residiendo dentro del propio país, ajustan su producción a estándares globales" (García Canclini, 1993:259 citado en Vergara y Vergara, 2002:2).

Por otra parte, no cabe duda que, a partir de este tipo de manifestación, en los talleres se construyen tradiciones culturales como producto simbólico, lo que hoy llamamos artesanía (Turok, 1996, Canclini, 1990, Novelo, 1993) y que analizando el contexto de producción local se confirma que la filiación del oficio es transmitida por línea generacional o "agnática" en la que se reservan la herencia, basado en la tenencia de la tierra, es decir, terrenos y parcelas constituyen ese legado territorial sobre el que se extrae la principal materia prima (el barro). Esa transmisión de conocimiento es reflejado en un $100 \%$ y puede entenderse como el conjunto de patrones que una generación hereda de las anteriores, enseñados por medio de la familia, los amigos, la escuela, las instituciones, entre otros (Boas, 1964:180).

Igualmente, cabe indicar que a pesar que San Juan de Oriente forma parte inevitable de la llamada cultura "neo-artesanal"5 sus talleres, además, de ser el lugar de convivencia de las familias también, su edificación está lógicamente pensado para desarrollar objetos, para la experimentación, para la creación y producción de innúmeras piezas con el mismo diseño, o de lo contrario, de artesanías únicas y exclusivas, es decir, habrá piezas en proceso, otras que se desechan, que se desbaratan, que se reaprovechan, que están en el devenir, (Freitag, 2012:161). De tal modo, que la dualidad aprender y transmitir funciona como elemento integrador, en otros términos, una especie de transmisión continúa de saberes tradicionales.

5. Los gustos del público consumidor son de carácter "selecto" fuertemente influenciados por los medios de comunicación 


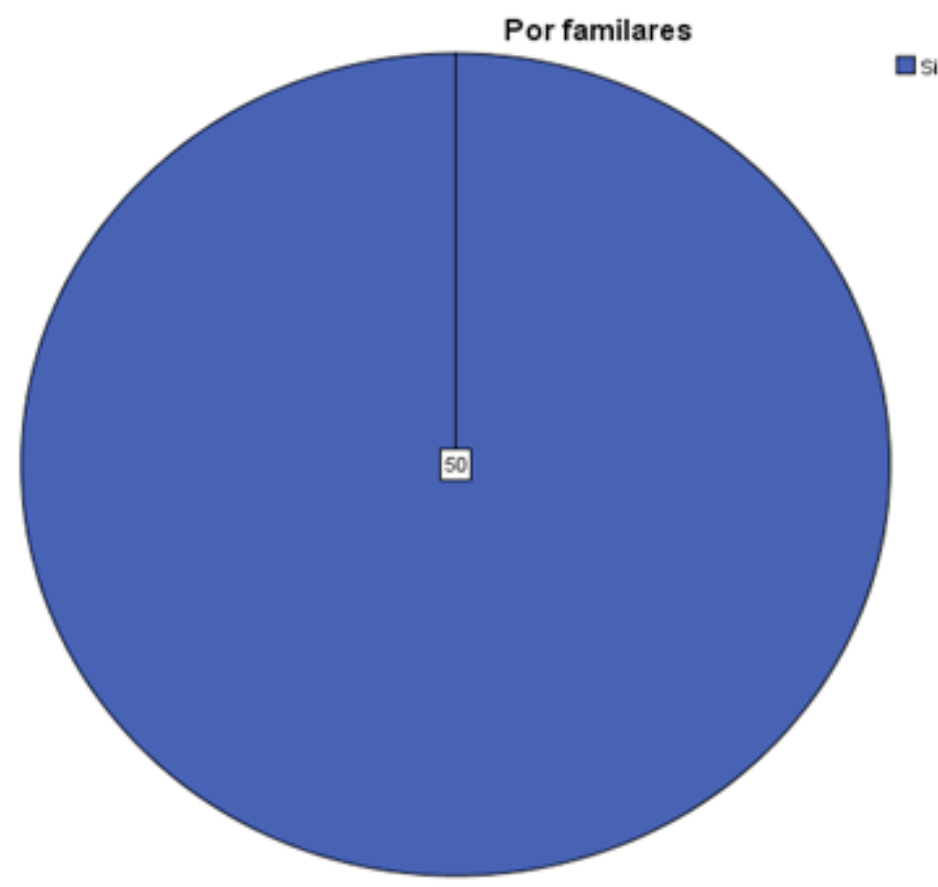

Gráfico 2.Transmisión del conocimiento artesanal

En todo caso, la alfarería local representa el rostro cultural y material del país, es la síntesis de toda experiencia adquirida y transmitida con una identidad forjada con el ímpeto ancestral Chorotega, pero que también simboliza una actividad de autogeneración de ingresos importantes para sus creadores ya que es la principal actividad económica del municipio (61.2\%) y suma en el día a día, a decir, para el sustento alimenticio, vestimenta, servicios básicos, educación y otros.

\section{El catálogo de reproducciones: Una contribución al trabajo artesanal alfarero}

En consecuencia, la propuesta de un catálogo cerámico que integrará elementos morfológicos y decorativos de origen prehispánico, se presenta en este estudio, justamente porque contribuye a la revitalización del arte alfarero local mediante la enseñanza de valores y conocimientos propios de su cultura. La confección de este texto tiene su fundamentación epistemológica y metodológica en la Historia del Arte, ya que toda creación artística resulta de la actividad humana y de propósitos varios: estéticos, comunicativos, ideas, emociones y otros.

Precisamente, por ser el tema artesanal alfarero portador de la identidad local de sus pobladores, y porque vivimos en un contexto cambiante, tiene repercusión práctica la introducción de este material didáctico, pues la tradición alfarera es más competitiva y globalizada, justamente por el contexto de modernidad que se rebela contra la función normalizadora de la tradición, porque la cultura modernista ha llegado a penetrar los valores de la vida cotidiana (Habermas, 1980:3). 


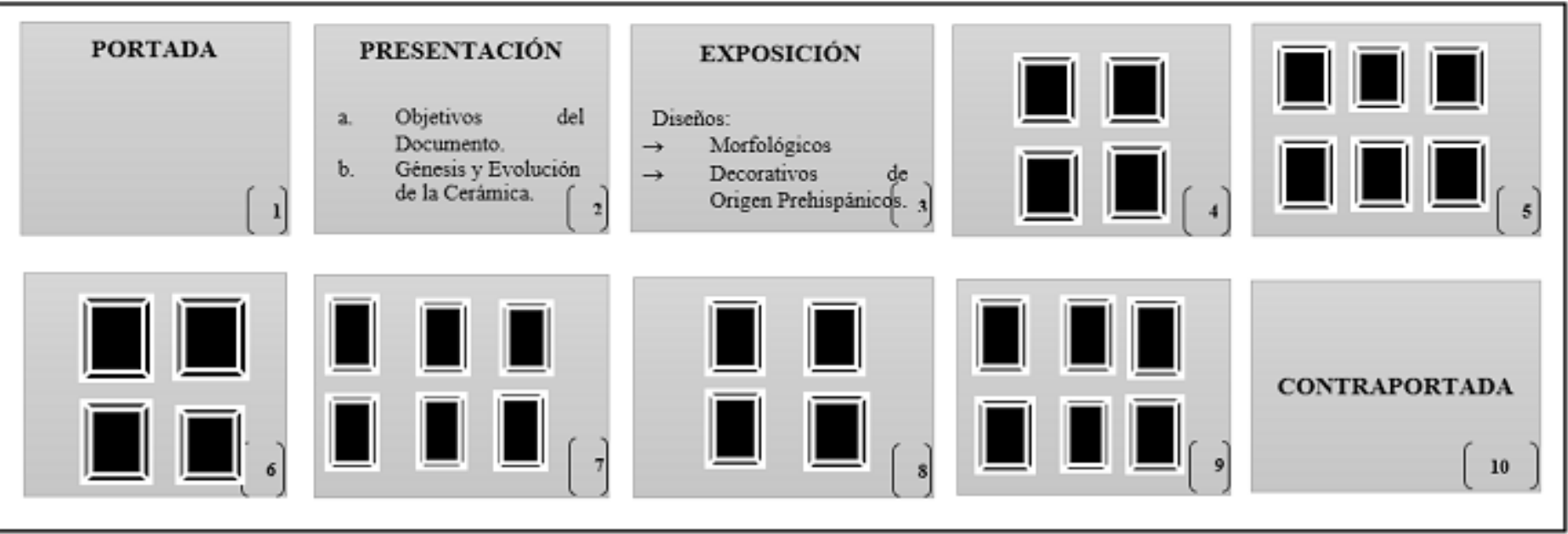

Esquema 1. Propuesta de catálogo cerámico: morfológico y decorativo de origen prehispánico (material de reproducciones)

Las intenciones de la propuesta desean mostrar una mirada de cómo el artesano puede alimentarse de los aportes de investigaciones arqueológicas y otros a fines, sobre todo, de aportes simbólicos y estéticos que permitan al artista encontrarse con aquel saber tradicional, "el de siempre", ese que lo acompaña desde antes de nacer.

\section{Observaciones finales}

De acuerdo con lo analizado, los hallazgos en cuestión han permitido revelar y explicar la naturaleza de la producción alfarera en los talleres de San Juan de Oriente, frente a la perspectiva de lo que unos llaman "globalización", otros, "sociedad civil global", "trasnacionalismo", "cosmopolitismo" o bien, "modernidad". Sin importar que término sea el más idóneo para abordar este escenario, lo cierto es que arrastra a la producción alfarera hacia dos realidades opuestas, una positiva y otra negativa: la universalidad y la uniformidad (Krazov, 2003:240), lo que explica hoy la diversificación de estilos cerámicos y la variabilidad en las técnicas de manufactura supeditados al uso del torno alfarero, así como la sustitución de pigmentos naturales por colorantes sintéticos.

En consecuencia, la dinámica capitalista de fines del siglo XX, y con ello el tema del turismo en el país, estableció una demanda de mercado que estimuló a los artesanos locales a redescubrir técnicas innovadoras, además de las ya aprendidas en la escuela-taller, es decir, se trabajaron en conocimientos ancestrales como las llamadas "réplicas precolombinas" con exponentes como Gregorio y Norwin Bracamonte, además, de la técnica del "chancomido" en los año 90, bajo la autoría de Helio Gutiérrez y otros, con técnicas como el "acrílico" y el "calado inciso". La dualidad de ese mercado afectó la persistencia de las iconografías cerámicas, pero también trajo como resultado, la existencia de tipologías cerámicas heterogéneas creando "artesanos por desesperación y no por elección", lo que en la práctica, para la producción artesanal resulta asfixiante ya que esa saturación de piezas en el mercado hacen que el sector sea poco atractivo por la presencia de 
diversos competidores, lo que genera que los intermediarios tengan alto poder de negociación, complicando los canales de comercialización.

Ese escenario explica la necesidad de apostar por una organización gremial coherente, consciente de las debilidades y fortalezas que tiene el sector, por lo que es oportuno la participación de la municipalidad e instituciones afines que permitan avanzar en temas de organización, asistencia técnica y acercamiento con entes financieros considerando que quienes componen este oficio por lo general viven como pueden casi siempre pobres, con poca o nula escuela, en sitios carentes de servicios elementales y sin ninguna protección social (Novelo, 1993:73). Es válido reconocer las políticas promovidas por el gobierno de Reconciliación y Unidad Nacional, no obstante, de acuerdo al ímpetu y hallazgos emergidos, explican que, el escenario de las ferias es bastante competitivo y no todos los artesanos se animan a participar de ellos.

Finalmente, la producción alfarera ha experimentado en la actualidad la necesidad de un nuevo diálogo entre el diseño y las formas cerámicas en la que la tradición del artesano tiene mucho que aportar a la cultura actual sin que esto signifique un retraso en los diseños, al contrario, pretende retroalimentar el trabajo hecho a mano con el instrumental para poder potenciar a ambas, por lo que la producción alfarera local expresa, a simple vista, elementos perceptivos de originalidad que se entremezclan y ponen de manifiesto el tema de la identidad colectiva de sus pobladores.

\section{REFERENCIAS BIBLIOGRÁFICAS}

Balladares, S. y Lechado, L. (2005). Historia Antigua de la Región del Pacífico, Centro y Sur de Nicaragua. El Oriente y Medio día de Nicaragua: Aportaciones al Estudio de su Historia. 1ra edición. Managua: grupo editorial ACENTO S.A.

Beck, U. (1998). ¿Qué es la Globalización? Falacias del Globalismo, Respuestas a la Globalización. Editorial Paidós, Barcelona. España.

Benedetto, A. (2006). Identidad y Territorio: Aportes para la Re-Valorización de Procesos de Diferenciación Productiva en Áreas de CoExistencia Geográfica. Mendoza, Argentina.
Boas, F. (1964). Raza, Lengua y Cultura y Primeras Manifestaciones Culturales. Cuestiones Fundamentales de Antropología Cultural. Ediciones Solar/Hachette. Buenos Aires, Argentina. Recuperado de: www.teebuenosaires.com.ar/biblioteca/ franz-boas-CFdA.pdf

Castegnaro de Folletti, A. (1992). La Alfarería Tradicional de la Paz Centro. En Romero V. Persistencia Indígena en Nicaragua. $1^{\mathrm{a}}$ .Ed.-Managua: CIDCA-UCA. 306pp.

Carrasco, G. (2002). La circulación de las Mujeres Alfareras en el Norte de Nicaragua. $1^{\mathrm{a}}$.Ed. Tlaxcala, México. 
Cremonte, M. (1985). Alcances y Objetivos de los Estudios Tecnológicos en la Cerámica Arqueológica. Anales de Arqueología y Etnología 38/40: 179-217. Mendoza.

Constenla, A. (1994). "Las lenguas de la Gran Nicoya". Vínculos 18-19 (1-2). Costa Rica.191-208pp.

Ferrero, L. (2000). Costa Rica Precolombina. Editorial Costa Rica, San José.

Ferrero, L. (1987). Costa Rica Precolombina: Arqueología, Etnología, Tecnología, Arte. $-2^{\mathrm{a}}$. Ed.- Editorial Costa Rica, San José. 489pp.

Flick, U. (2004). Introducción a la Investigación Cualitativa. Madrid, España. Ediciones Morata y Fundación Paideia. 99pp.

Freitag, V. (2012). Los Espacios de Recreación Artesanal: El Caso de los Talleres de Alfareros Tonaltecas en México. Revista Chilena de Antropología Visual. N¹9, 161-175. Recuperado de: http://www.rchav.cl/ img19/imprimir/freitag_imp.pdf

García Canclini, N. (2006). Culturas Híbridas. Estrategias para Entrar y Salir de la Modernidad. 17ª Reimpresión. México.

García Canclini. (1990). Culturas Hibridas: Estrategias para entrar y salir de la Modernidad. México. Recuperado de: https://cbd0282.files.wordpress. com/2013/02/culturashibridas.pdf
García Rosselló, J. (2008, Diciembre). Etnoarqueología de la Producción Cerámica. Identidad y Territorio en los Valles Centrales de Chile. MAYURQA, 32 (08): 1-328pp. Universitat de les Illes Balears, Palma. Recuperado http://www.academia.edu/9997879/ E T N OAR QUEOLOG\% C $3 \% 8$ DA_ DE_LA_PRODUCCI\%C $3 \% 93 \mathrm{~N}_{-}$ CER\%C3\%81MICA._Identidad_y_ territorio_en_los_valles_centrales_de_ Chile

Habermas, J. (1980). La Modernidad, un Proyecto Incompleto. En Foster, $\mathrm{H}$. (Editor) "La Posmodernidad". Editorial Kairós, México, 1988. Recuperado de: https://unidadcinco.files.wordpress. com/2014/07/la-modernidad-unproyecto-incompleto-habermas.pdf

Hammersley, M y Atkinson, P. (1994). Etnografía. Métodos de Investigación. Barcelona: Paidós Básica.

Krazov, E. (2003). Globalización e Identidad Cultural. Revista Mexicana de Ciencias Políticas y Sociales, XLVI Enero-Abril. Recuperado de: www.redalyc.org/articulo. oa?id=42118711

Novelo, V. (1993). Las Artesanías en México. $1^{\mathrm{a}}$. Ed.-Editorial: Gobierno del Estado, Instituto Chiapaneco de Cultura/Tuxtla Gutiérrez, Chiapas, México. 88pp. D.F.: McGraw-Hill. 
Orton, C., Tyers, P. y Vince, A. (1997). La Turok, M. (1988). Como Acercarse a la Cerámica en Arqueología. Ed. Crítica, Artesanía. Editorial Plaza y Janes, S. A. de Barcelona. C.V. México.

Palomar, B y Gassiot, E. (1996). Recursos Instrumentales para la Investigación. Curso de Titulación de Arqueología, Managua, Nicaragua.

Taylor, S. y Bogdan, R. (1987). Introducción a los Métodos Cualitativos de Investigación. Editorial Paidós, Buenos Aires, Argentina.

Velásquez, R. (2003). Estética Aborigen. FUNDARTE. Caracas, Venezuela. 144pp.

Vergara, J y Vergara, J. (2002). Cuatro Tesis sobre la Identidad Cultural Latinoamericana. Una Reflexión Sociológica. Recuperado de. www.revistacienciasociales.cl/archivos/ revista12/.../revista12_articulo6.d 